\title{
APPLICATION OF THE BALANCED SCORECARD CUSTOMER PERSPECTIVE IN AN AIRPORT ENVIRONMENT
}

\author{
Branko MIKULA*, Iveta VAJDOVA, Alica TOBISOVA \\ Technical University of Kosice, Faculty of Aeronautics, Rampova 7, 041 21, Košice, Slovak Republic \\ *Corresponding author. E-mail: Branko.Mikula@tuke.sk
}

\begin{abstract}
In general, it is more expensive and time consuming to acquire a new business instead of building upon an existing relationship. It is absolutely necessary to understand what passengers' perception of airport services is in case an airport aspires to assess its handling services performance. Customer perspective in the Balanced Scorecard (BSC) method is an ideal tool to gather all data how passengers feel about airport handling and other hospitality processes at airports. This paper deals with BSC customer perspective being applied by airport managers as an essential part of their business strategies. The goal of this paper is a presentation of a role of customer's impression as a valuable forward-looking indicator in BSC's customer perspective. The paper recognizes passenger survey and KPI methods as leading research tools for assessing of customer services performance. Importance Performance Analysis (IPA) characterized in this paper, is considered as an efficient method for performing the research analysis. The paper asserts that passengers stand a very influential part in an overall process of airports' business strategy decision making.
\end{abstract}

Keywords: Balanced Scorecard; customer perspective; customer satisfaction; customer sustainability; KPI; IPA

\section{INTRODUCTION}

The Balanced Scorecards (BSC) method is both a strategic management system and a system of measurement. This method focuses on the measurement of achievements of strategic goals which formulate a scheme of airport successful or failing business activities. There are a lot of measurement methods and results evaluation to sum up companies' productions. Financial measures are important, but those only give a part of the picture about a company's production. Fundamental construction elements of the BSC have come from an idea to see a company as a single consistent unit, where individual parts act in the specific balanced system. Financial measures are more like lag indicators about what has already happed in a company. This method is dealing with a strategic vision and breaks it into pieces of every day steps within a company. Company's vision and strategies are translated into objectives, targets, measures, and initiatives for every perspective. A study by Figge et al (2001) give examples of generic categories of lagging and leading indicators. According their study lagging indicators in financial perspective are revenue growth, productivity growth, and asset utilization; in customer perspective there are lagging indicators: market share, customer acquisition, customer retention, customer satisfaction, and customer profitability. In perspective of internal processes, there are innovation process, operations process, and post-sale service process, and finally in learning and growth perspective there are employee productivity, employee satisfaction, and employee retention. Also the same team of authors proposed leading indicators in customer perspective as product attributes, customer relationship, and image and reputation; in internal processes perspective as quality indicators, time indicators, and cost indicators, and finally in learning and growth perspective, there are employee potentials, technical infrastructure, and climate for action. The authors do not propose any leading indicators in financial perspective! Oslon et al (2002) in their research suggest that the need for innovation is well understood among prospector firms. They continue with a prediction that high-performing prospectors place greater emphasis on the customer perspective than do low 
performers. They confirm that the attention they pay to their customers is something what separates high- from low - achieving prospectors. Also applicable in BSC customer perspective is a presentation of Kelemen et al.(2021) who stand to an opinion that it depends on the requirements for the choice of specialists and information methods which are proposed to allow for obtaining a set of input data for the work of the developed models, namely evaluation of ways of thinking; assessment of theoretical knowledge; assessment of practical knowledge; assessment of knowledge in the theory of pedagogy, psychology and communicative competence; and assessment of narrowly specialized skills. Bento et al (2013) explain that an important outcome measure in the customer perspective is market share. Also the authors explain the critical mass of customers as a situation when value propositions are fulfilled. The study of Norton and Kaplan (1993) states that managers using the BSC do not have to rely on short-term financial measures as one and only indicator of company's performance. BSC method and its perspectives as well as applicable research methods are discussed in the next chapters.

\section{BALANCED SCORECARD PERSPECTIVES}

The BSC is a strategy planning and management system which organizations use not only to prioritize various projects, businesses, services, but also communicate what they are trying to accomplish. Companies implement the BSC to align the day-to-day work and to make sure everyone is doing in-line with existing strategies as well as measurement and monitor progresses towards strategic targets. The BSC method includes (Fig.1) financial perspective, customer perspective, internal processes perspective, and learning and growth perspective. A strategic management, as an essential part of the BSC method, has five significant process elements. This process starts at a stage when (1) defining a vision which models all subsequent elements. This is some commencing spot, where everything subsequent originates. Then, the process enters to (2) conduct the company internal analyses. After analyses results are available, managers can continue with (3) building of a strategy. This strategy is (4) implemented and finally (5) monitored. Venkatraman and Ramanujam (1986) propose that strategy-level performance measurement should include both financial and operating measures. According to Simons (1991), management control systems have three major elements: (1) setting performance standards, (2) measuring performance against the standards, and (3) taking corrective action if the standards are not being achieved. Thus, the systems provide feedback on the effectiveness of competitive activities, enable learning from internal and market-oriented experiences, and provide guidance for strategic change and renewal. Performance measurement is central to the management control process for any business. According a study of Ernst and Young's Centre for Business Innovation by Daly (1996) it was proved that investment analysts who considered nonfinancial as well as financial performance indicators were more accurate in their earnings estimates than those who just used financial indicators. The BSC suggests to examine an organization from four different perspectives. Learning and grow perspective reflects an overall corporate culture. The perspective includes tasks as awareness of employees about latest company strategies, mission of a company, moods within a department, trainings, promotion scheme etc. Perspective of internal business processes gives an answer how a production is managed, and what products and services a company offers. Customer perspective considers customers, their wishes and satisfaction as main drives for managers to decide what services and production are worth at a time. Customers tell what they want to see in corporate's offer. Financial perspective, also called a lag indicator, but with a powerful stand in the BSC model. The perspective has a strong influence on other three in the BSC method. The financial perspective is a material form of what a company is producing or what services are provided. 


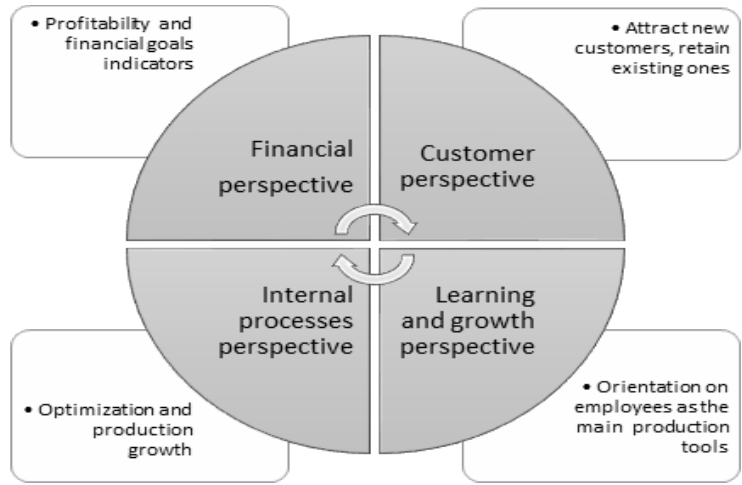

Figure 1 Four perspectives of BSC

Source: author

\section{A ROLE OF BSC CUSTOMER PERSPECTIVE THROUGH AIRPORTS' PASSENGER PROCESSES}

The existence of loyal customers is a vital element for profit making airports. Airports have a variety of direct and indirect customers such as carriers, retailers, tenants and others. But the most important customer segment element is a passenger. An in-depth understanding of a customer profile is extremely important for airports planning and making a maximum revenue. Lovelock (1999) in his study explains that customers, before they purchase a service, have expectations about service quality that is based on their individual needs, past experiences, and word-of-mouth recommendations. Domestic and international passengers are those whom an excellent customer service is dedicated to. Passengers' behaviour is affected by variables like nationality, age, destination, and reasons for travel. It is obvious that there are different needs of departing passengers comparing to arriving ones. Also transiting passengers have different needs. The customer perspective in the BSC model is predominately focused on passengers who have some personal or IT interface contact with an airport. According Hoffman (2001), companies who show high customer satisfaction ratings seem to have the ability to insulate themselves from competitive pressures, particularly price competition. Nowadays, more and more airlines request passengers to do their home check-in. This system of managing predeparture formalities was found as fast, comfortable, effective and manpower saving. Passengers proceed directly to gates, after have entered a departure hall. One, in past mandatory break at check-in counter, is now skipped. Anyway, if a passenger does not hold a home printed boarding pass, or baggage tag, or this is a passenger with special needs, or travelling with a live animal, sport or music equipment or similar, still must contact serviceable check-in counter and register himself for a flight. Security control is mandatory process, and the most important one. Passengers' security is at utmost importance of all airports. Security controls represent a sophisticated system of actions to make airports and flights safe. Gates configuration, space, seating comfort, and relaxing zones particularly weight on passengers' feelings, and satisfaction. This was very briefly described passenger journey through the airport on departure. From a moment a passenger passes factious airport area borders, a mix of impressions and experiences start to model a final judgement how the airport was found, and how satisfying its services were. Figure 2 shows 6 most important airport stop spots before passengers boarding an airplane. 


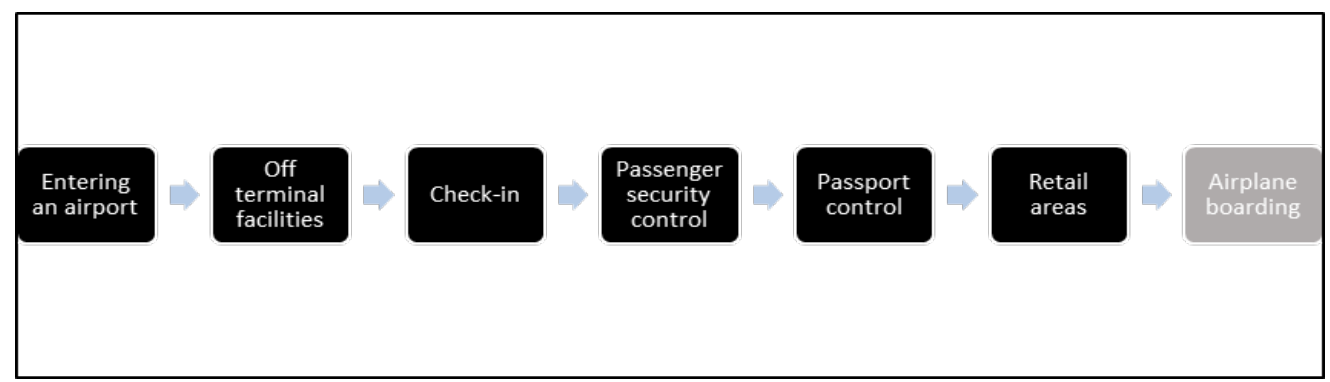

Figure 2 A departing passenger standard breaking points at an airport

The customer perspective is responding to passenger experiences. This experience has become a major focus of all airports around the globe. The implementation of this perspective in the BSC model begins with a vision statement. A company's vision must be clear, comprehensive and manageable. For example, Adelaid's airport vision is 'To be a top tier Airport Business Centre in Asia Pacific, recognised for delivering exceptional outcome to our customers, partners, shareholders and community'. But as commented by one of its managers, the airport does not have trend to be the biggest in the region but its top tier was explained as building a successful airport which meets, and whenever possible exceeds customer expectations. Finally, after the vision is set, the process of building this perspective can continue with planning strategy. There is a large spectrum of methods for collecting passenger experiences data after receiving airport services. Since a questionnaire is a method that could address unlimited number of passengers, remains anonymous, and costs friendly, then it is recommended to apply an adequate type of a questionnaire. Wiredja (2015) admits that most researches have applied tailored surveys and questionnaire as their data collection method. A pre-test or pilot study is necessary to check a questionnaire meets the research criteria. A good questionnaire should adapt objectives of the research into questions and answers should translate data to explore information defined by objectives. Sato (2003) in his study states that the design of questionnaires for survey research represents one of the most challenging aspects in terms of accuracy in measuring respondents' perception.

Figure 3 shows example of objectives that are considered with set target satisfaction rate. Target achievements are measured by various tools. Some of them are listed in below Figure 3. Passengers are usually very sensitive to any disturbance and discomfort. Generally agreed a $90 \%$ satisfaction rate (target) also reflects to a very competitive airline environment. Measured results sourced from KPIs reports, surveys, and questionnaires, lead to a decision which improvement initiatives are to be chosen next.

\begin{tabular}{|c|c|c|c|}
\hline Objectives & Measures & Targets & Initiatives \\
\hline Strengthen core business & & & \\
\hline Increase passenger loyalty & \multirow{9}{*}{$\begin{array}{l}\text { passenger } \\
\text { satisfaction } \\
\text { survey, } \\
\text { questionnaires, } \\
\text { KPI }\end{array}$} & \multirow{9}{*}{$\begin{array}{l}90 \% \\
\text { satisfaction } \\
\text { rate }\end{array}$} & \multirow{9}{*}{$\begin{array}{l}\text { increase quality, prompt } \\
\text { services, improved arrival } \\
\text { services, modernization of } \\
\text { airport facilities, marketing, } \\
\text { customer services } \\
\text { innovations }\end{array}$} \\
\hline Attract new passengers & & & \\
\hline Build passenger relation & & & \\
\hline Identify passenger needs & & & \\
\hline Meet and exceed passenger expectation & & & \\
\hline $\begin{array}{l}\text { Implement quality off airport services } \\
\text { (home check-in) }\end{array}$ & & & \\
\hline $\begin{array}{l}\text { Improving assistance for passengers with } \\
\text { reduced mobility and other disabilities }\end{array}$ & & & \\
\hline Smooth flight irregularity handling & & & \\
\hline Safety and security improvement actions & & & \\
\hline
\end{tabular}

Figure 3 Elements of BSC customer perspective in an airport environment 


\section{MEASURING CUSTOMER SATISFACTION}

Customer service is a core component of excellent customer experience. Airports measure customer satisfaction applying a variety of tracking and measuring methods. Measuring must be performed on regular basis. Data collected using quantitative and qualitative methods are carefully stored and evaluated. Measurement is efficient as long as costs are outweighed by the benefits generated by the 'information updated' through the gathering and processing of data. Subjects included in the measurements are directly involved either as a customer service provider, recipient or both. A selection of a proper measuring tool requires some knowledge and experience of a research team. Top customer satisfaction measurement tools applicable at an airport environment are customer surveys, and Key Performance Indicator. Customer surveys conducted via questionnaires have advantages and disadvantages. The BSC method is a complex system which needs to understand and influence the controllability of the processes to achieve agreed goals. Regarding this matter, Kelemen et al. (2021) emphasize to apply an innovative hybrid competency assessment model based on fuzzy logic and a network for neuro-fuzzy assessment. Their innovative hybrid competency assessment model is based on fuzzy logic and a network for neuro-fuzzy assessment. It is a technological model for evaluating the competencies of specialists, taking into account the influence of human factors on the processes of personnel selection and system management. In 1977 Martilla and James developed a technique called Importance-Performance Analysis (IPA). The IPA technique is recommended as appropriate for achieved data analysing. According Yildiz (2011) 'Performance' represents the user's perception of the quality of services delivered by the organization, while the 'Importance' refers to the assessment of the importance of those services by users. In relation to customer satisfaction, Oliver (1997) suggests that consumer satisfaction to be a target criterion variable when measuring attributes of importance and performance. Oh and Parks (1997) state that consumer satisfaction is also modelled as a function of the disparity between expected and experienced performance in expectancydisconfirmation theory. The mean values of passengers' perceptions are divided on IPA model of four quadrants. Quadrant I (High Importance/High Performance) represents attributes of strengths of an airport. Quadrant II (High Importance/Low Performance) represents key areas that need to be improved with top priority. Quadrant III (Low Importance/Low Performance), any of the attributes that fall into this quadrant are not important and pose no threat to the organizations. Quadrant IV (Low Importance/High Performance) denotes attributes that are overly emphasized by the organizations.

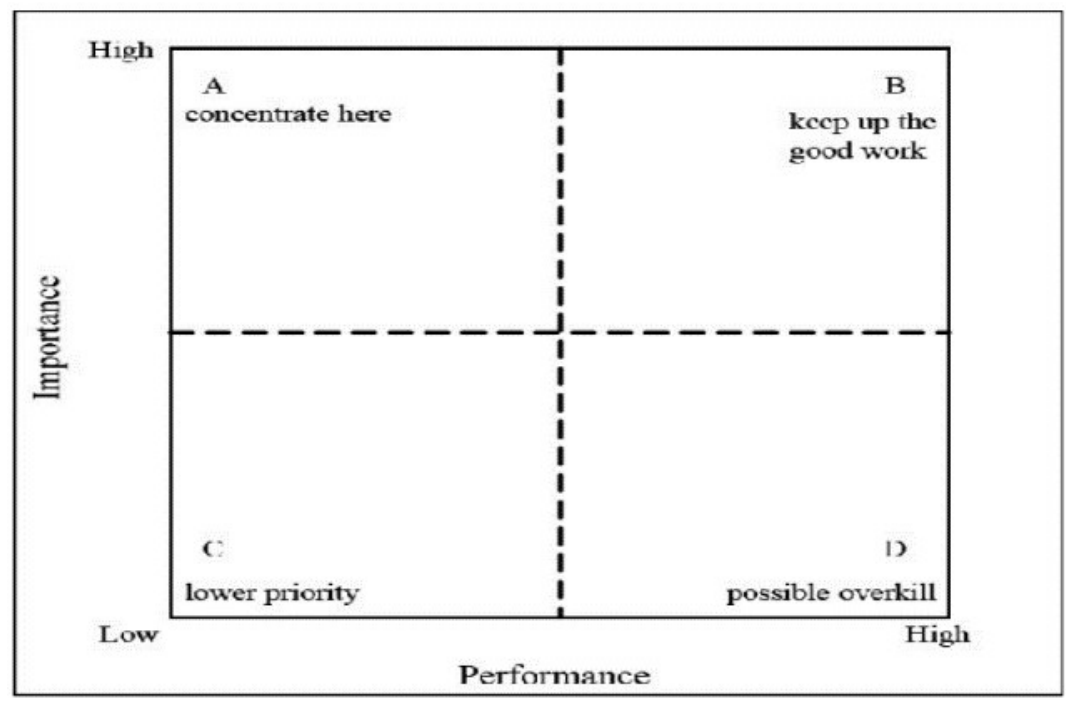

Figure 4 Importance-performance analysis (IPA)

Source: Martilla and James (1977) 


\section{CONCLUSION}

Opinions toward services offered at the airports differ between business and leisure travelers, and frequent and infrequent travelers. The customer perspective in the Balanced Scorecard method has its important role in measuring how airport services can impact on passengers. This perspective is a perfect combination of passengers' experiences and managers' ideas how to meet and even exceed customers' expectations. Competitors with their research tool, market analyses, and a will to risk, can very easily devastate activities of any airport in a region or even in a whole country. The Balanced Scorecards considering external factors and transform them into the internal processes which remain balanced with other perspectives and keep that system live and effective. Airports must have a complex system of measurements which unify lagging indicators with ones which show how airport is able to mix vision, strategy and initiatives in one stream. New customers as well as lost ones are best mirror how an airport is able to perform its services. There is a very thin line between customers' satisfaction and disappointment. This thin line is parallel with one between retaining a customer and lose one. The BSC recognizes sources, explains necessary processes, develops measurements, sets targets, and supports links between causes and results. Every airport is faced with the challenge of allocating their limited resources to various segments of need. Airports must decide which action to pursue by weighing the importance of each need to the others. This BSC customer perspective helps airports to acknowledge the importance of airport uniqueness in the passenger experience, and why they should invest in it.

\section{References}

[1] Airport Service Quality. Customer Experience Brouchure. 2017. ACI. Montreal. Canada.

[2] Bento, A. - Bento,R. Validating Cause-and-Effect Relationships in the Balanced Scorecard. Academy of Accounting and Financial Studies Journal. 2013. Vol. 17 (3). PP. 45-55.

[3] Bisbe, J. - Barrubés, J. The Balanced Scorecard as a management tool for assessing and monitoring strategy implementation in health care organizations. 2012. Vol. 65(10). PP. 919-27.

[4] Daly, D. Performance measurement and management. Management accounting .1996. 09 issue. PP. 65-66.

[5] Hendricks, K. \& et al. Adoption of the Balanced Scorecard: A Contingency Variables Analysis. Canadian Journal of Administrative Sciences. 29(2). 2012. PP.124-138. Available at: https://doi.org/10.1002/cjas.229

[6] Hoffman, K. D. - Bateson J. E. Essentials of services marketing: concepts, strategies, \& cases. 2nd Edition. South-Western: Thomson Learning.2001. Chapters 12-13.

[7] Kaplan, S. - Norton, P. Putting the Balanced Scorecard to Work. 1992. Harvard Business review.

[8] Kelemen, M. \& et al. Model of Evaluation and Selection of Expert Group Members for Smart Cities, Green Transportation and Mobility: From Safe Times to Pandemic Times. Mathematics. 2021. 9. 1287. Available at: https://doi.org/10.3390/math9111287

[9] Lovelock, H. Principles of service marketing and management. 1999. New Jersey: Prentice-Hall, Chapter 5.

[10] Oliver, R. L. Satisfaction: a behavioral perspective on the consumer. 1997. Irwin: McGrawHill Company.

[11] Olson,E. - Slater,S. The balanced scorecard, competitive strategy, and performance. Business Horizons. 2002. Indiana University Kelley School of Business.USA.

[12] Sato, Y. Questionnaire Design for Survey Research: Employing Weighting Method.2003. The International Symposium on Analytic Hierarchy Process (ISAHP). Hawaii.USA. 
[13] Simons, R. Strategic orientation and top management attention to control systems. 1991.Strategic Management Journal.

[14] Venkatraman, N. - Ramanujam,R. Measurement of business performance in strategy research. 1986. Academy of Management Review 11/4 (October). PP. 801-814.

[15] Wiredja, D. A Holistic Approach to Improve Balance Scorecard in Measuring Performance of Listed Companies. 2010. The Parahyangan International Accounting and Business Conference. Bandung. Indonesia.

[16] Yildiz, S. M. An importance-performance analysis of fitness centre service quality: Empirical results from fitness centres in Turkey. 2011.African Journal of Business Management. 5.

Received 06, 2021, accepted 07, 2021

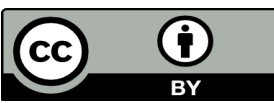

Article is licensed under a Creative Commons Attribution 4.0 International License 